\title{
Generic Competition in the US Pharmaceutical Industry
}

\author{
ATANU SAHA, HENRY GRABOWSKI, HOWARD BIRNBAUM, \\ PAUL GREENBERG and ODED BIZAN
}

\begin{abstract}
We develop a simultaneous equations estimation framework to understand the interactions among generic entry, prices, and market shares. We base our estimates on a panel data sample of 40 brand-name drugs that first experienced generic competition during the period July 1992-January 1998. We find that generic share and price are simultaneously determined, while the number of generic entrants is a key determinant of generic market share and the generic-to-brand price ratio. In addition, we find generic competition to be particularly intense for blockbuster drugs, which experience significantly more generic entrants, price erosion, and generic penetration than other drugs.
\end{abstract}

Key Words: Generic Entry; Competition.

JEL Classifications: I11, L11.

\section{Introduction}

Generic competition has intensified in the US prescription drug industry and become a major source of health care cost savings since the mid-1980s. The Congressional Budget Office (CBO) estimated that purchasers saved between \$810 billion in 1994 by substituting generics for brand name drugs (CBO, 1998). Recently, several leading brand name drugs have experienced generic competition

The authors wish to thank Ernst Berndt and Arthur Havenner for their excellent comments on an earlier version of the paper. Research support from Mark Spelber and Sarah Whitney and editing support from Amelia Greenberg are gratefully acknowledged. Any errors that remain are ours.

Atanu Saha, Analysis Group, 10 Rockefeller Plaza, 15th Floor, New York, NY 10020, USA; e-mail: asaha@analysisgroup.com, Henry Grabowski, Duke University, Department of Economics, Box 90097, Durham, NC 27708, USA; e-mail: grabow@econ.duke.edu, Howard Birnbaum, Analysis Group, 111 Huntington Ave., 10th Floor, Boston, MA 02199, USA; e-mail: hbirnbaum@analysisgroup.com, Paul Greenberg, Analysis Group, 111 Huntington Ave., 10th Floor, Boston, MA 02199, USA, e-mail: pgreenberg@analysisgroup.com, Oded Bizan, Microeconomic Analysis, 21 Orchard Street, Cambridge, MA 02140, USA. 
- e.g., Prozac, Vasotec and Taxol - and many more commercially significant brand name drugs will face generic competition in the next five years.

In this paper, we seek to understand the process of generic competition better by developing a model that captures the interactions among generic entry, prices, and market shares using a simultaneous equations framework. The model is estimated on a panel data sample of 40 drugs first exposed to generic competition over the period July 1992-January 1998.

The next section of this paper considers the historical and institutional factors encouraging the growth of the generic industry and summarizes prior findings reported in economic literature. Section 3 discusses the structure of the model and our estimation methodology. Section 4 describes the characteristics of the dataset and our sample. Section 5 discusses the estimation results. Section 6 contains a preliminary analysis of the impact of generic entry on brand price. The final section provides a brief summary and conclusions.

\section{Background}

\subsection{Important Industry Developments}

The growth of the generic drug industry over the past two decades has been affected by important changes on both the demand and supply sides. One key event was the passage of the Drug Price Competition and Patent Term Restoration Act of 1984, better known as the Hatch-Waxman Act. This act significantly reduced the costs and time of entry for generic drugs by establishing an Abbreviated New Drug Application (ANDA) procedure. With an ANDA, generic firms need only show that their products are bioequivalent to the branded product in order to gain Federal Drug Administration (FDA) approval. ${ }^{1}$ In addition, the law established a research exemption so that generic firms could perform their bioequivalence testing and receive conditional FDA approval prior to the expiration of the brand product's patents. The 1984 law also tried to strike a balance between generic price competition and drug innovation by providing brand name firms with the opportunity for patent term extension to compensate for time lost during the clinical testing and regulatory approval stages. ${ }^{2}$

On the demand side, the development of the generic industry has been aided by the growth of managed care and the more intensive coverage of prescription drugs by health insurers. ${ }^{3}$ Pharmacy benefit management firms (PBMs) have evolved as managers of pharmaceutical reimbursement programs for both HMOs and employers and have actively promoted the use of generic drugs as a costsaving measure (Berndt, 2002). Generic competition has also been encouraged through various benefit designs, including a tiered formulary in which generics are placed in the least costly co-payment tier. ${ }^{4}$ PBMs also provide incentives to pharmacists in the form of higher fees for generics, compared to branded products. ${ }^{5}$ In addition, PBMs often monitor and attempt to alter physicians' prescribing habits among those who disproportionately prohibit generic substitution. Grabowski and Mullins (1997) found that these various incentive measures can save payers $10 \%$ or more of their total drug budget.

Thus, there have been powerful institutional forces at work accelerating the degree of generic competition since the mid-1980s. This is reflected in the fact that $47 \%$ of prescription drug units consumed in the United States in 1999 were generic products, compared to only 19\% in 1984 (PhRMA, 2001: 61). With several 
widely prescribed branded products scheduled to go off patent in the next five years, the percentage of generic utilization is likely to increase in the years ahead.

\subsection{Prior Economic Studies of Generic Competition}

Several economic studies have examined the characteristics and determinants of generic competition after the passage of the 1984 Hatch-Waxman Act. Caves et al. (1991) conducted an early exploratory analysis of generic competition using a sample of 30 drugs that went off patent between 1976 and 1987. Their analyses spanned the period prior to Hatch-Waxman and a few years after its passage. They found that the initial generic drug entered the market at a significant discount to the branded product ( $40 \%$ on average) and this discount grew larger as the number of generic competitors expanded over time. However, even with a significant number of generic competitors in the market, the average market shares ${ }^{6}$ of the generic products were relatively small in this period. In this regard, their analysis was consistent with a number of studies of the pre-1984 period that found the impact of generic competition on branded sales to be very limited. ${ }^{7}$

Several papers have focused on generic price. In two related studies, Grabowski and Vernon $(1992,1996)$ examined a sample of 40 branded products that faced generic competition between 1984 and 1993, when the intensity of generic competition increased significantly. ${ }^{8}$ Using a regression model in which the number of generic competitors was driven by the expected profitability of entry, they found that the price of a generic product tended toward marginal cost over a multi-year time frame. ${ }^{9}$ In a recent paper, Reiffen and Ward (2002) estimated a structural model of the relation between generic drug prices and the number of ANDA approvals, and concluded that eight or more ANDAs were generally sufficient to cause generic prices to converge to long run marginal cost.

Another subject of prior studies has been generic market share. Grabowski and Vernon (1996) found that the speed at which generics captured market share was positively related to the size of the brand product's pre-entry sales, the therapeutic class of the product, and the calendar date of generic entry. Greater rates of generic utilization were observed for more recent time cohorts of brand products. In particular, by the early 1990s, generic shares averaged about two-thirds of a molecule's unit sales one year after the initiation of generic competition.

Fiona Scott Morton examined generic entry decisions in two recent papers. In the first paper, Scott Morton (1999) showed that firms are more likely to venture into markets in which they have some experience, e.g., in form, therapy or ingredient. In addition, firms have a tendency to enter large markets and markets where the drug treats a chronic condition. In a second paper, Scott Morton (2000) looked at factors that might thwart generic entry, including switching costs, FDA regulations, and brand firm advertising. Using a sample of 98 drugs with patent expirations from 1986 to 1992, she found that generic entry was positively related to brand revenue and price elasticity, and negatively affected by FDA regulations. ${ }^{10}$ She also found no evidence that brand advertising has deterred generic entry.

A number of investigators dating back to Caves et al. (1991) have considered the response of brand firms to generic entry and whether branded firms have pursued entry-deterring strategies. There is little evidence to support the hypothesis of entry deterrence. First, with respect to promotional activities, branded firms typically curtail most of their expenditures, usually beginning in 
the pre-entry period (Caves et al., 1991). ${ }^{11}$ Ellison and Ellison (2000) find that the trends in advertising and product proliferation are non-monotonically related to the probability of generic entry: advertising is reduced and presentation proliferation increased in the period preceding patent expiration among drugs that face an intermediate probability of entry. Second, there is scant evidence that brand firms take pre-emptive actions or match generic prices, except when they offer selective discounts to their large institutional customers (CBO, 1998). Rather, most studies have found that branded drug firms continue to raise prices after generic entry, although there is some disagreement about whether generic entry has positively or negatively affected the rate of increase in these prices. ${ }^{12}$ Grabowski and Vernon observe specific cases where brand name firms have pursued a two-tier strategy, entering the generic market either through a subsidiary firm or in partnership with a generic firm. Even in these latter situations, however, entry has not been effectively deterred and generic price competition has remained intense.

\subsection{Objectives of Our Analysis}

Our study builds on the studies discussed above, but contributes to the literature in several dimensions. First, we explicitly account for the interaction between three key variables: generic entry, generic share, and generic-to-brand price ratio. We posit that these variables are part of a simultaneously determined system; specifically, generic entry affects the share of generic suppliers and the price of generics. These two variables are then endogenously determined. That is, generic share depends on, and is influenced by, generic price. While a few papers in the existing literature have acknowledged the endogeneity of generic entry, ${ }^{13}$ prices, or shares, to our knowledge ours is the first paper to adopt a simultaneous estimation procedure to address the issue of the endogeneity of all of the key variables. Our empirical results clearly show that generic share influences and is influenced by prices, corroborating our model's econometric estimation framework.

Second, our study examines a relatively large sample of drugs that experienced generic competition between July 1992 and January 1998. The analysis of more recent data is particularly relevant in light of the marked growth of generic drug sales fuelled by the dominant role of managed care and PBMs in the 1990s.

Finally, we adopt an estimation framework that is appropriate for panel data. Our estimation approach allows and corrects for heteroskedasticity and serial correlation of errors. That is, we allow for idiosyncratic differences across drugs (cross sectional units) through the heterogeneity of error variances. Additionally, since we have time series observations on each drug, we allow for drug-specific serial correlation of errors. The ordinary least squares (OLS) model is a special case of this more general estimation approach. Our results demonstrate that the OLS estimation framework yields, in many cases, seriously erroneous inferences about the determinants of generic competition.

Our empirical results provide valuable insights into the determinants of generic entry, prices, and generics' market share. We find generic competition to be particularly intense for 'blockbuster' drugs, which we define as drugs having pre-generic annual sales of $\$ 500$ million or more. Specifically, we find that blockbuster drugs average two more generic entrants annually compared with nonblockbusters. We further find that the number of generic entrants, in turn, directly affects the level of generics' share and price. Blockbuster drugs thus experience not only significantly more generic entrants, but also more price erosion and 
generic penetration than non-blockbuster drugs. We also find that the extent of $\mathrm{HMO}$ coverage has a positive impact on the market share garnered by the generics. Additionally, generic prices are significantly and positively related to the costs of drug production.

Our results also include a preliminary analysis of brand prices. In contrast to prior studies' findings based on data from earlier time periods, our results indicate that brand prices do respond to generic competition: each additional entrant on average is associated with a $0.2 \%$ decline in brand price. Nevertheless, unless the number of generic competitors is large, brand prices continue to rise in absolute terms. Consistent with prior studies, we do not find any evidence of entrydeterrent pricing by brand manufacturers.

\section{Econometric Model Specification}

The objective of the econometric model is to explain the determinants of three key variables for each drug: $P, S$, and $N$, where $P$ denotes the average generic-tobrand price ratio, $S$ represents the share of the group of generic substitutes of a branded drug, and $N$ is the number of generic manufacturers of that compound.

The number of generic manufacturers for the $i^{\text {th }}$ drug at time $t$ is defined as follows:

$N_{i t} \equiv N_{i t-1}+E_{i t}$,

where $E_{i t}$ is the number of generic entrants for $i^{\text {th }}$ drug at time $t$. The number of entrants, in turn, is determined by:

$E_{i t}=f\left(N_{i t-1}, X_{i}^{E}, \varepsilon_{i t}^{E}\right)$

where $X^{E}$ is a set of exogenous variables related to the conditions of entry faced by generics, and $\varepsilon^{E}$ denotes random errors. All variables on the right hand side of (2) are thus pre-determined, that is, (2) is not a simultaneous equation and therefore can be estimated directly.

By contrast, for each drug the generic-to-brand price ratio $(P)$ and the share for all generics $(S)$ are jointly-determined (i.e., endogenous) variables. The simultaneous equation framework determining these variables is:

$P_{i t}=g\left(S_{i t}, N_{i t}, X_{i t}^{P}, \varepsilon_{i t}^{P}\right)$

$S_{i t}=h\left(P_{i t}, N_{i t}, X_{i t}^{S}, \varepsilon_{i t}^{S}\right)$

where $X^{P}$ and $X^{S}$ are sets of exogenous variables that affect the price ratio and generic share, and $\varepsilon^{P}$ and $\varepsilon^{S}$ are random errors. Note that while the number of generics $(N)$ affects the generic-to-brand price ratio and generic share, it is a predetermined variable since it is fully determined by information available at time $t-1$.

Equation (3) includes exogenous variables affecting the intensity of price competition on the supply side of the market. Equation (4) includes exogenous variables affecting the intensity of demand by managed care and other purchasers. Equation (3) is identified by excluded demand side shifts (i.e., HMO coverage), while equation (4) is identified by excluded cost shifters (i.e., manufacturing costs). 


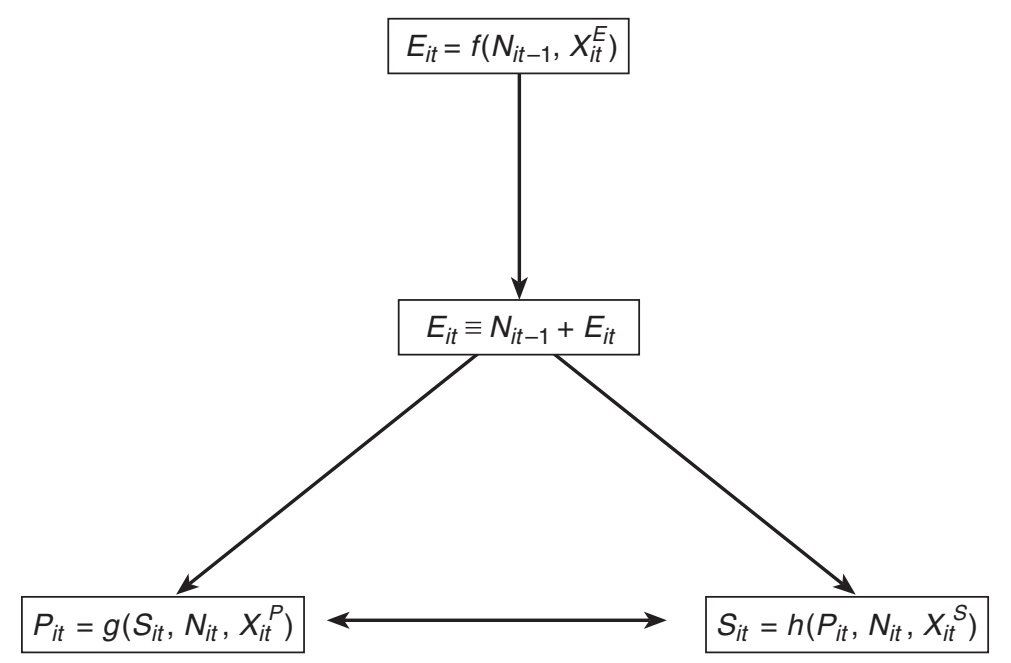

Figure 1. The interaction between entry $(\mathrm{E})$, number of generics $(\mathrm{N})$, generic share $(\mathrm{S})$, and generic-to-brand price ratio $(\mathrm{P})$

Figure 1 summarizes the relationships between the key variables, $N, P$, and $S$, in the econometric model. The direction of the arrows in the figure indicates the causality relationship. Thus, a one-directional arrow going from, say, $N$ to $P$ indicates that $N$ is exogenous to $P$. The two-directional arrow connecting $P$ and $S$ indicates endogeneity of these two variables.

We estimate equation (2) separately from (3) and (4). The latter two form a system of simultaneous equations, which is estimated using the instrumental variables (IV) regression approach. Each of these equations is estimated using both OLS and pooled time series cross sectional estimation methods, with appropriate correction for heteroskedasticity and serial correlation. In particular, we assume that in each equation, (2)-(4): $\varepsilon_{i t}=\rho_{i} \varepsilon_{i t-1}+u_{i t}$, where $u_{i t}$ is identically and independently distributed random error, and $V\left(\varepsilon_{i t}\right)=\sigma_{i}^{2}$. Thus, OLS is a special case wherein: $\rho_{i}=0, \forall i$, implying no autocorrelation, and $\sigma_{i}^{2}=\sigma_{j}^{2}=\sigma^{2}, \forall i, j$, implying homoskedasticity of errors.

\section{Data and Descriptive Analysis}

\subsection{Source Data}

The data for our analysis are primarily derived from an IMS Health information product entitled 'Generic Spectra.' IMS Health is a leading provider of information products to the pharmaceutical and healthcare industries. ${ }^{14}$ The Generic Spectra dataset has product shipment information for purchases made by pharmacies and hospitals, including units and revenues.

This dataset contains dollar and gram sales data for brand and generic drugs for, at most, three years before and three years after first generic entry. ${ }^{15}$ The brand drugs in the dataset first faced generic competition between July 1992 and January 1998. Our sample is restricted to oral drugs utilized primarily on an outpatient basis. While the original dataset included 41 drugs, we omitted one - Micronase (glyburide) - because it was launched in a co-marketing agreement with Diabeta 
(also glyburide). The list of drugs in our analysis, their therapeutic classification, and the manufacturer of the brand are reported in Table 1. We used these data to construct the key variables in our analysis, including brand price, generic price, generic share, market size, and generic-to-brand price ratio.

We measure generic share for a drug by dividing the sum of all generic manufacturers' sales (in grams) by the total sales (i.e., generic plus brand) of the compound. We calculate price as dollars per gram. We recognize that this differs from the definition of price used in previous studies. For example, Grabowski and Vernon (1992) have used the average cost per unit paid by drugstores and hospitals for the most frequently consumed dosage size of each compound. Frank and Salkever (1997) define price as the average revenue per extended unit, while Caves et al. (1991) identify the most popular dosage of each drug and then divide sales revenue by quantities sold in wholesale transactions (i.e., transactions involving pharmacies and hospitals) to compute an average price. Although our dollars-per-gram price does not account for the variation in prices arising from different dosage forms, it is the most relevant price for our analysis given that it captures the entire market for the drugs rather than a specific segment.

Data on the number of generic manufacturers of each drug come from IMS America's Product Directory in the Market Research database. These data include drugs' manufacturers and entry dates. ${ }^{16}$ We verified these dates using the Federal Food and Drug Administration's Orange Books. ${ }^{17}$

Data on HMO coverage come from PhRMA's Pharmaceutical Industry Profile (2000). It is an annual series based on IMS audits that reports third-party pharmaceutical reimbursement. We calculate the manufacturing cost variable from the Bureau of Labor Statistics (BLS) intermediate goods price index for basic inorganic chemicals, which we divide by the BLS pharmaceutical producer price index to express cost in real dollars. ${ }^{18}$

We created indicator (or dummy) variables for the various therapeutic classes to which the drugs belonged to capture the class-specific differences across drugs. We also created an indicator variable for the drugs Clozaril, Mexitil, Toradol, and Zarontin, because their usage is restricted due to the possibility of serious side effects, a disincentive to generic entry. Specifically, Clozaril has a high incidence of agranulocytosis, which makes patients susceptible to life-threatening infection. The drug is administered only through a process that mandates a weekly monitoring of the patients' white blood cell count. Mexitil is indicated only for patients with life threatening arrhythmia and its use can be initiated only in hospitals. Similarly, Toradol must be started in a hospital in IV form. Use of the oral form is limited to five days due to its potential for severe side effects, including bleeding ulcers. Zarontin can reduce the body's ability to manufacture certain blood cells that are important to fight infections and prevent bleeding. As a result, patients on Zarontin must have their blood levels monitored periodically. For each of these four drugs, Clozaril, Mexitil, Toradol, and Zarontin, the 'restricted usage' indicator variable takes a value of one; it is zero for all other drugs.

\subsection{Descriptive Statistics}

Table 1 lists all compounds in our dataset, the therapeutic classes to which they belong, and the brand manufacturers. The 40 brands in the sample belong to nine therapeutic classes and are manufactured by 20 pharmaceutical firms. The largest therapeutic class in the sample, Cardiovascular, has 14 compounds. 


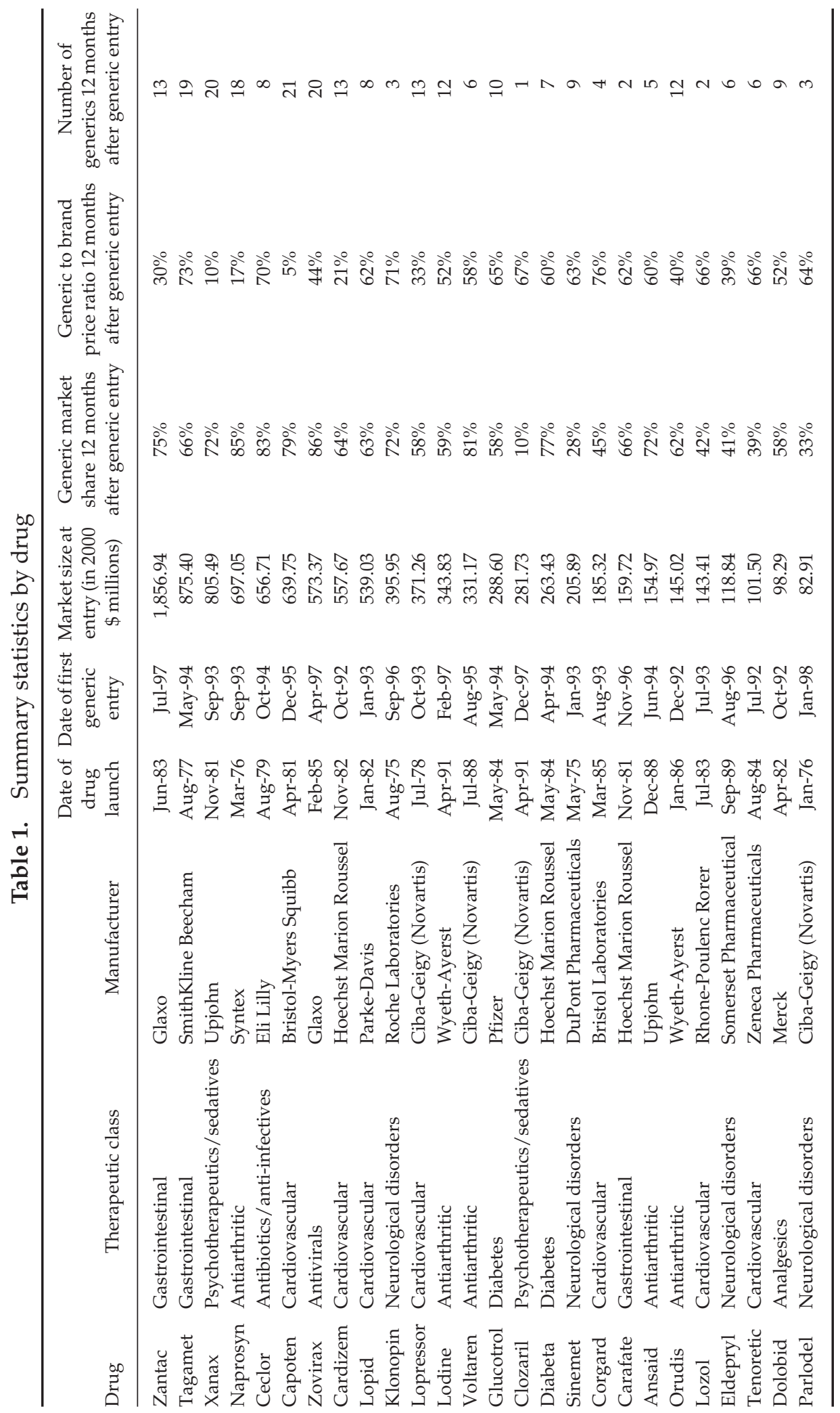




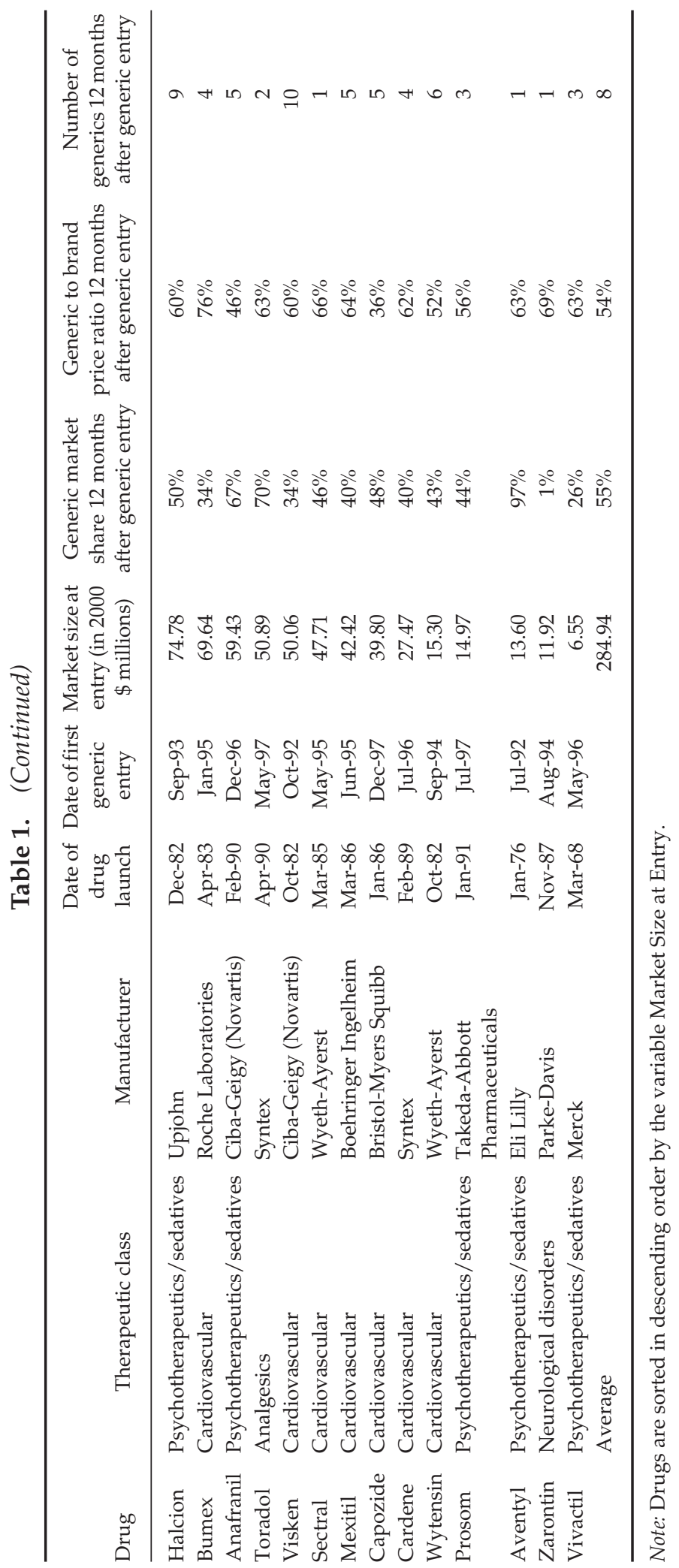


The branded drugs in the sample were launched between March 1968 (Vivactil, in the class of Psychotherapeutics/sedatives, launched by Merck) and April 1991 (Clozaril, launched by Novartis and Lodine in the class of drugs for Psychotherapeutics/sedatives, and by Wyeth-Ayerst in the class of Antiarthritics). The brands in the sample faced generic competition between July 1992 and January 1998.

Table 1 reveals considerable variability in entry rates across drugs. While some compounds are supplied by at least 20 generic firms within a year after generic entry occurs, for others there is only one. Table 1 also shows an association between entry rate and market size. ${ }^{19}$ The average annual sales by the brand prior to generic entry for drugs with at least 20 generic entrants are $\$ 673$ million. ${ }^{20}$ This figure drops to $\$ 101$ million $^{21}$ for drugs facing competition from only one or two generic entrants.

The statistics in Table 1 also suggest a strong association between entry rate and the generic-to-brand price ratio. The average generic-to-brand price ratio a year after the first generic entry for drugs with at least 20 generic suppliers is $20 \%$; by contrast, this ratio is $65 \%$ for drugs with two or fewer generics by the end of the first year.

Table 1 data reveal considerable variability in the degree of generic penetration across drugs. The average market share a year after the first generic entry for compounds with at least 20 suppliers is $79 \%$, while this share is only $47 \%$ for compounds with two or fewer generics. Even within the group of compounds that experienced very little entry, there are marked differences. During the first year after generic entry, both Aventyl and Zarontin experienced competition from only one generic manufacturer. But, the shares of these generics were $97 \%$ and $1 \%$, respectively, the highest and lowest one-year generic shares in the sample. Thus, although the statistics in Table 1 indicate a strong association between the number of generic entrants and both generic share and generic price, clearly there are other important determinants of these variables. We examine these through regression analysis in the next section.

Table 2 defines variables used in the regression analysis and contains postentry summary statistics. ${ }^{22}$ The minimum and maximum values of the key variables suggest a high degree of heterogeneity across drugs and over time. For example, for the 40 drugs in the sample, the number of generic competitors ranges between 1 and 27, the generics' share between $0.02 \%$ and $99 \%$, and the generic-to-brand price ratio between 0.05 and $1.13{ }^{23}$ These figures suggest a considerable degree of variability in the nature and extent of generic competition across drugs. The focus of the next section is an examination of the factors that explain this variability.

\section{Estimation Results}

This section first considers the determinants of generic entry and then discusses the impact of generic entry and other factors on the generic-to-brand price ratio and generic market share.

\subsection{Determinants of Generic Entry}

For most drugs in our sample, significant entry occurs after the first generic manufacturer has entered the market. Figure 2 a depicts the average number of 


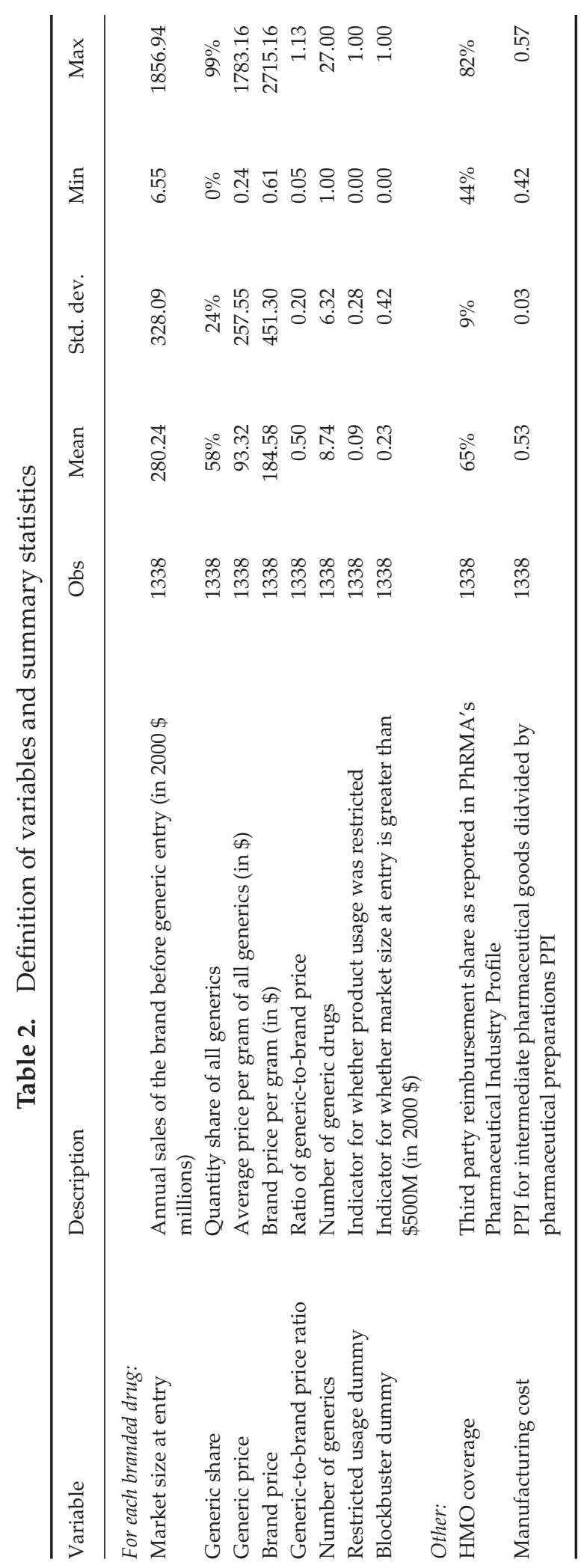




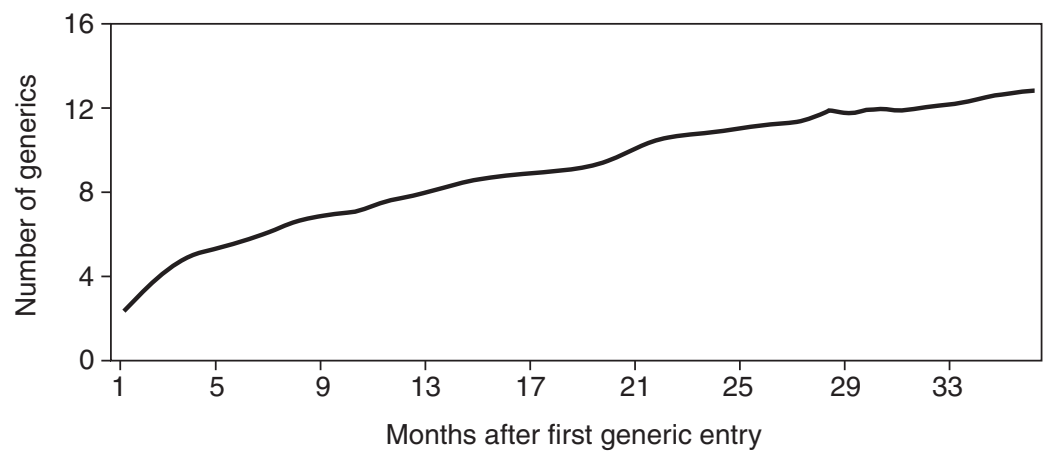

Figure 2a. Average number of generic drug manufacturers.

generics in the months following generic entry. As the figure shows, by the end of the first month, on average two generic manufacturers compete with the brand. Within four months the average number of generics exceeds five, and within a year it is close to eight. There is essentially no exit of generic firms observed in our panel data sample.

We base our entry variable on several factors. We hypothesize that entry depends in part on the number of independent firms marketing the drug through wholesalers and chain pharmacies. We expect early entry in particular to be strongly influenced by the size and profitability of the market prior to patent expiration, as well as other market pull factors. Additionally, FDA regulations affect entry. As previously stated, current entry is regulated by the HatchWaxman Act, which sanctioned bioequivalence testing and application for conditional approval prior to patent expiration. The law also allowed a generic supplier to enter the market not only through its own approved ANDA but also through a licensing arrangement with a firm that had an approved ANDA. Most of the 40 products in our sample have in fact considerably more generic suppliers than approved ANDAs, which suggests that many generic firms have entered crosslicensing deals in order to extend their product portfolios. In other cases, firms with approved ANDAs do not actually market the associated drugs, but act as formulators for several generic marketers. Importantly, the approval of an ANDA is not guaranteed and its timing is subject to uncertainty; the median annual FDA approval time for ANDAs during the period 1992 to 1997 varied between 1.5 years to over 3 years. ${ }^{24}$ The result is variability in the timing of initial generic entry into the market.

Depending on both the economic and regulatory factors influencing a particular drug's entrance into the market, there may be several simultaneous generic entrants during the first month of generic competition (typical for very large selling products), or generic entry may be spread out over time. In any event, as the number of cumulative generic entrants increases, generic shares will rise, generic prices will decline, and the attractiveness of further entry will decline. Hence, the economic conditions in the market will be an important factor influencing later entry decision, both for firms with late pending ANDAs as for those with opportunities to enter through a licensing arrangement. For this reason we include the number of existing generic manufacturers (lagged one period) as a pre-determined variable affecting entry. ${ }^{25}$ We expect the number of generic 
incumbents to exhibit a negative effect on the number of entrants in any time period.

A key factor determining an entrant's potential demand is the size of the market, which we define as the annual dollar volume (in 2000 dollars) of brand sales prior to the first generic entry. Based on this market size, we create an additional indicator variable, 'blockbuster,' which takes a value of one for drugs whose sales exceeded $\$ 500$ million in the year prior to the first generic entry, and zero otherwise. We control for therapeutic-class-specific differences across drugs through therapeutic-class dummies.

We report the estimation results in Table 3. Model 1 results are from the OLS estimation framework. In Model 2, we used the pooled time series cross sectional (or generalized least squares (GLS)) estimation approach. ${ }^{26}$ We do not report the coefficient estimates of the therapeutic-class dummies.

A likelihood ratio test unambiguously rejects Model 1, which is nested as a special case in Model 2. Although for most coefficients the estimates from the two models do not differ in sign or significance, the effect of the number of generic incumbents is much smaller in the OLS specification.

The estimation results suggest that a key determinant of entry is the number of generic incumbents; the estimated coefficient of this variable is negative and highly significant. This result suggests that subsequent entry decreases as the number of incumbents increases. Our results also highlight the importance of market size as a determinant of entry: larger markets, especially blockbuster drugs, attract significantly more generic entrants. Brand names with pre-entry annual sales exceeding $\$ 500$ million attract, on average, two more entrants per year. $^{27}$

Not surprisingly, entry is less intense for drugs with usage restrictions imposed by the FDA. The coefficient of the 'restricted usage' dummy variable is

Table 3. Analysis of the determinants of generic entry

Dependent variable: number of generic entrants

\begin{tabular}{|c|c|c|c|c|}
\hline \multirow[b]{3}{*}{ Regressor } & \multicolumn{2}{|c|}{ Model 1} & \multicolumn{2}{|c|}{ Model 2} \\
\hline & \multicolumn{2}{|c|}{ OLS } & \multicolumn{2}{|c|}{$\begin{array}{c}\text { Pooled Time-Series Cross- } \\
\text { Sectional, GLS }\end{array}$} \\
\hline & Coef. & t-statistic & Coef. & z-statistic \\
\hline Number of generics (lagged) & -0.0682 & -13.63 & -0.1194 & -14.06 \\
\hline Market size at entry & 0.0003 & 2.32 & 0.0006 & 1.59 \\
\hline Blockbuster dummy & 0.7787 & 6.54 & 0.8655 & 3.40 \\
\hline Restricted usage dummy & -0.4200 & -4.77 & -0.5263 & -5.05 \\
\hline Intercept & 0.7347 & 6.28 & 0.9466 & 7.39 \\
\hline Adj. $R^{2}$ & & 0.1439 & & \\
\hline Log-likelihood value & & -1647.51 & & -1282.26 \\
\hline Number of observations & & 1338 & & 1338 \\
\hline
\end{tabular}

Chi-squared test statistic for OLS vs. pooled GLS model using LR test=730.50 (p-value=0.0000)

Chi-squared test statistic for the null: all therapeutic-class dummies are zero $=58.84(\mathrm{p}$-value $=0.0000)$

Notes: Therapeutic-class dummies are included in both models but are not reported. 
negative and statistically significant. We also find that there are significant differences in the levels of entry across therapeutic-classes; the joint null hypothesis that the coefficients of the therapeutic-class dummies are each equal to zero is unambiguously rejected.

These results are, in general, consistent with those in prior studies. For example, Frank and Salkever (1997) and Grabowski and Vernon (1992), among others, also found that market size was a significant determinant of entry. Likewise, our findings about entry are generally consistent with those of Scott Morton (1999), although her analysis differed from ours in the scope of the data used. Namely, our sample included only drugs for which entry had occurred, whereas Scott Morton examined a relatively large sample of drugs, only some of which had experienced generic entry. Her study was thus broader than ours on the issue of entry, and her results provide valuable insights into generic firms' decisions on whether to enter the market for a compound. The finding unique to our study is the importance of the number of generic incumbents as a determinant of entry.

\subsection{Analysis of Generic Prices}

Several prior studies have examined the impact of generic entry on prices. Caves et al. (1991), Wiggins and Maness (1994), and Grabowski and Vernon $(1992,1996)$ have found the prices of generic drugs to be substantially lower than those of branded drugs, and that the generic-to-brand price ratio falls with generic entry. Frank and Salkever (1997) show that while brand prices increase following generic entry, the average price of generics falls. As a result, the generic-to-brand price ratio declines over time.

Consistent with these previous findings, our analysis indicates that the average generic-to-brand price ratio for the drugs in our sample falls continuously following generic entry (see Figure $2 b$ ). Furthermore, as the entry rate slows down after the first year, so does the decline in the price ratio. A month after the first generic entry, the average price of generics for all 40 drugs in the sample is $76 \%$ of the brand price; by the end of the first year it is $54 \%$; by the end of the second year it is $41 \%$.

As before, we estimate our equation using first the OLS (Model 1) and then the GLS (Model 2) assumptions about estimation errors. The dependent

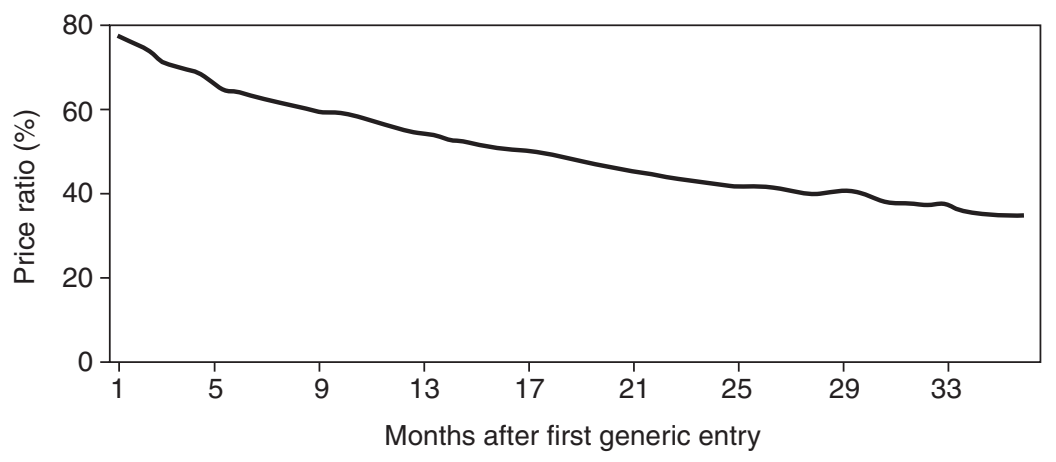

Figure $\mathbf{2 b}$. Average generic-to-brand price ratio. 
variable in both models is the logarithm of the generic-to-brand price ratio. To address the issue of simultaneity between prices and shares, we adopted an instrumental variables approach in estimating the system of equations in (3) and (4). ${ }^{28}$ In all models we include therapeutic-class dummies but do not report their coefficients.

Table 4 contains the results of the estimation of price equation (3). As noted earlier, the OLS model (Model 1) is nested as a special case in the GLS model (Model 2), and a likelihood ratio test unambiguously rejects the OLS framework in favour of GLS. This is an expected result given the pooled time series cross sectional nature of the data. Model 2 results indicate that both generic market share and the number of generic entrants are significant determinants of the generic-to-brand price ratio. A lower price ratio is associated with higher generic share and, on average, each additional generic manufacturer induces nearly a $2.3 \%$ monthly decrease in the value of the generic-tobrand price ratio. ${ }^{29}$ This result is consistent with the economic reasoning that the degree of competition is positively related to the number of producers in the market.

Table 4 results also suggest that price competition is particularly intense for blockbuster drugs. The estimated coefficient for the blockbuster indicator variable is negative, large (in absolute value), and highly significant. The positive coefficient of the manufacturing cost variable reflects the fact that costs are an important determinant of generic prices. In particular, if input costs decline relative to the producer price index, generic-to-brand price ratios also decline. This is consistent with the highly competitive market structure for generic drugs. Finally, the estimation results reveal significant differences in price erosion across therapeutic classes; the joint null hypothesis that the coefficients of the therapeutic-class dummies are each equal to zero is unambiguously rejected.

\subsection{Analysis of the Market Share of Generics}

Generic entry affects brand market share both directly and indirectly. To the extent that each new entrant provides an additional substitute to the brand, it may induce consumers to switch. As noted above, entry also intensifies competition among generics, driving prices down, which in turn induces switching from brand to generics.

Several previous studies have examined brand to generic switching. For example, Caves et al. (1991) find that while brand share drops following generic entry, the share reduction is relatively small compared to the price differential. Grabowski and Vernon (1996) find that the share of generics has been increasing over time, as do Reiffen and Ward (2002) and other researchers. One of the main reasons postulated in the literature is the rapid growth in the coverage of pharmaceuticals through managed care. In this regard, Mortimer (1997) found that the demand for prescription drugs in the managed care sector is much more price elastic than in other market segments, including the self-paid sector. Her results support the finding that managed care incentives have been very effective in shifting users to generic products when the branded version goes off patent.

As Figure 2c indicates in our sample, we observe a significant shift away from the brand following the introduction of generic substitutes. Within a month after the first generic enters the market, the average share of gram sales attributable to 
A. Saha et al.

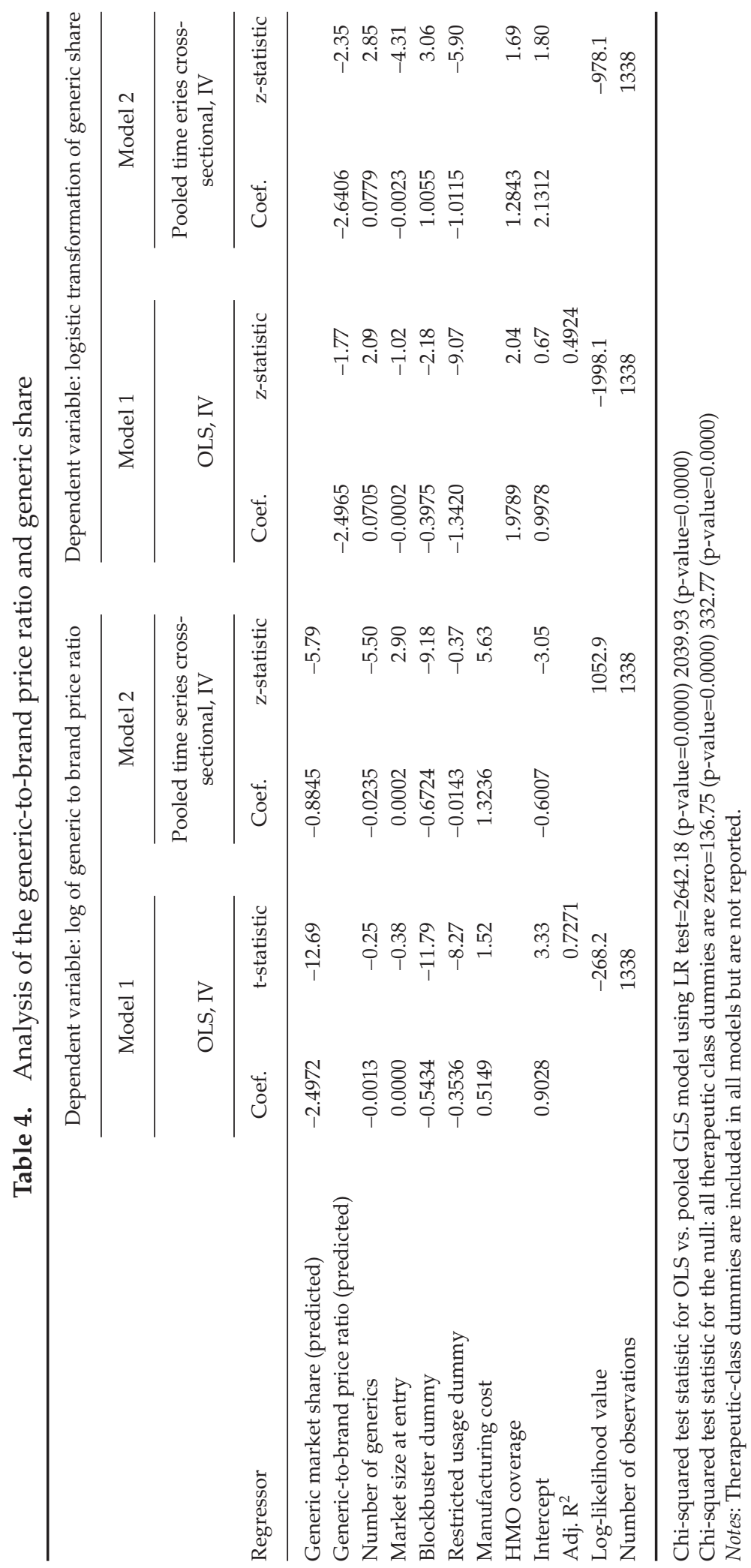




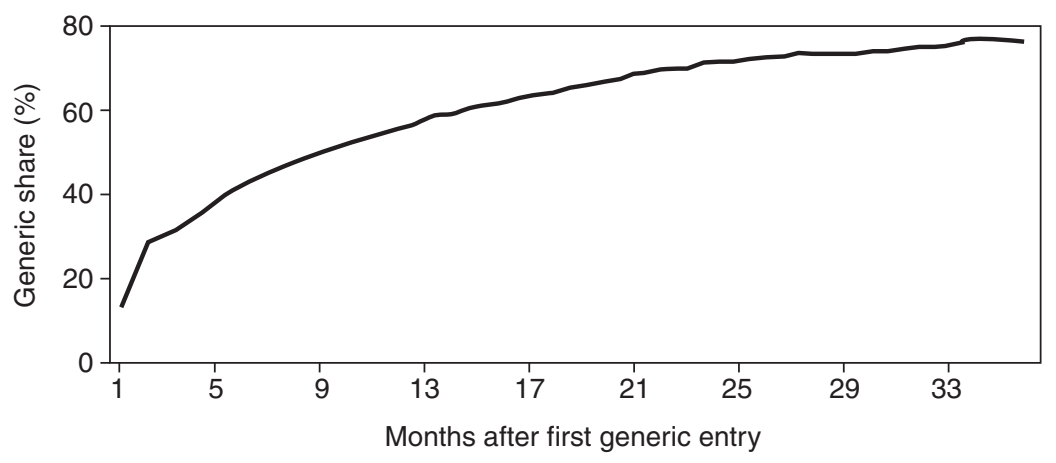

Figure 2c. Average generic share in gram sales

all generics reaches $14 \%$. Within six months, it reaches $43 \%$, and by the end of the first year, 55\%.

Because the explained variable in the generic share estimation equation is bounded between zero and one, we use the logistic functional form in estimation. That is, we use the transformation $\operatorname{Ln}\left(\frac{S}{1-S}\right)$ as the dependent variable, where generic share is denoted by $S \in(0,1)$. The transformation allows the right hand side of the estimation equation to be a linear function of the variables and coefficients but does not affect the sign of the coefficients. Since we model generic share as a function of generic-to-brand price ratio, which is endogenous, we adopt an instrumental variables estimation framework. As in the price equation, we estimate the share equation using both OLS (Model 1) and GLS (Models 2) estimation error assumptions.

Our results show that a likelihood ratio test in the generic share equation unambiguously rejects OLS. For Model 2, the coefficient of the (predicted) generic-to-brand price ratio is negative and highly significant. Additionally, the coefficient of the variable 'number of generics' is positive and significant, suggesting that generic share increases with entry. ${ }^{30}$ The results also suggest that blockbuster drugs experience more demand for generic products, resulting in significantly higher generic market share. As expected, the 'restricted usage dummy' variable's coefficient is negative and significant, which suggests that, for selected drugs with special conditions deterring entry, generic share is significantly lower. We also find that there are significant differences in the levels of generic penetration across therapeutic classes. That is, the joint null hypothesis that the coefficients of the therapeutic-class dummies are each equal to zero is unambiguously rejected.

The price and share equation estimation results shown in Table 4 support the simultaneous equation framework set out in (3) and (4): generic share is found to be a significant determinant of price, and price an important determinant of share. Although this result is eminently plausible and consistent with economic theory, it has received surprisingly little attention in the empirical literature on generic competition in the pharmaceutical industry. Additionally, the number of generic entrants and the size of the market are found to be important determinants of both generic-to-brand price ratio and generic share. 


\section{Impact of Generic Entry on Brand Prices}

Geroski (1995) reviews empirical evidence on the effect of entry for a variety of industries and argues that the immediate price response of incumbents to entry is selective. Previous studies of pharmaceutical markets reveal mixed evidence concerning brand price response to generic entry. While Caves et al. (1991) and Wiggins and Maness (1994) show that generic entry induces a statistically significant reduction in brand prices, Grabowski and Vernon (1992) and Frank and Salkever (1997) find that brand prices either do not change or increase after generic entry.

Following Grabowski and Vernon (1992), we estimate the following model:

$$
\ln \left(\frac{p_{B}}{P P I}\right)_{i t}=\beta_{0}+\beta_{1} t+\beta_{2} t \cdot A F T E R_{i t}+\delta X_{i t}+\varepsilon_{i t}
$$

The dependent variable is the natural logarithm of the brand price deflated by the Pharmaceutical Price Index. On the right hand side, $t$ is a time trend, AFTER is a dummy variable that takes the value of one after generic entry and zero otherwise; and $X$ is a vector of therapeutic-class dummies. Thus, $\beta_{2}$, the coefficient of the variable $t$. AFTER, indicates the difference in the rate of brand price change before and after generic entry, and would be negative if the rate of brand price change slowed after entry.

We report estimation results of equation (5) in Table 5. Models 1 and 2 are the OLS and the GLS estimation approaches, respectively. In both cases, the estimated coefficients of therapeutic-class dummies are not reported. The sample used to estimate (5) includes both pre-entry and post-entry observations for each drug.

OLS estimation results suggest that, on average, real brand prices do not respond to generic entry - the difference in the rate of change before and after generic entry is not statistically significant. However, this result does not hold when one adopts a correct estimation framework; the GLS estimate of $\beta_{2}$ indicates that entry does affect brand prices. On average, we find that generic entry induces a $2.2 \%$ lower rate of annual change for deflated brand prices. To further investigate the effects of generic entry on brand prices, we estimate the following regression model:

$$
\ln \left(\frac{p_{B}}{P P I}\right)_{i t}=\alpha+\beta N_{i t}+\delta X_{i t}+\varepsilon_{i t}
$$

The right hand side of this model contains $N_{i t}$, which is the number of generics selling drug $i$ at time $t$ and, as before, $X$ is a vector of therapeutic-class dummies. Estimation results are also reported in Table 5. The sample used to estimate this model only includes post-entry observations.

In Table 5, Model 3 and Model 4 correspond to the OLS and the GLS estimation results for (6), respectively. Unlike OLS, the GLS result indicates that the number of generics does affect brand price: each additional entrant is associated with an approximately $0.2 \%$ decline in average deflated brand price. ${ }^{31}$ Thus, assuming an entry rate of one generic per month, ${ }^{32}$ our estimates imply an approximately $2 \%$ annual price drop as result of entry. 


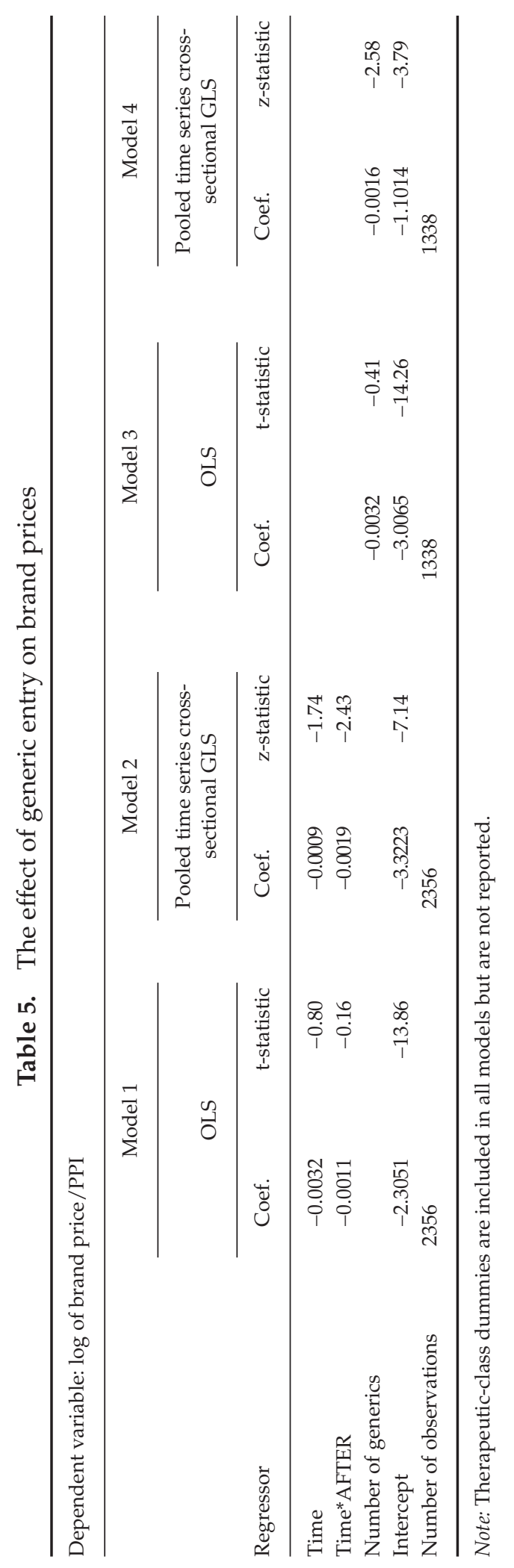




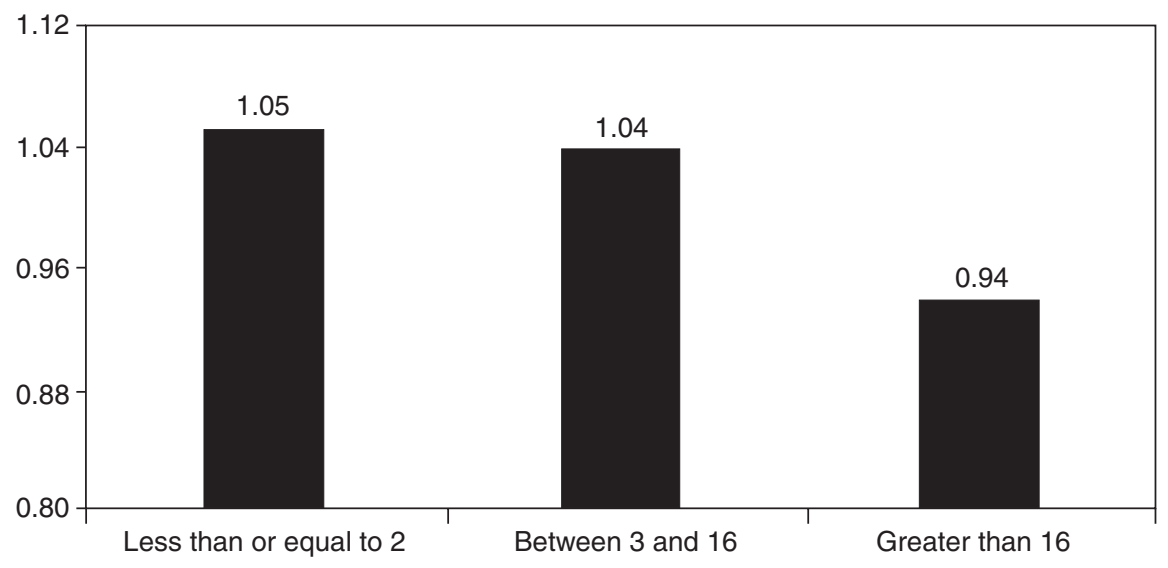

Number of generics

Figure 3. Relationship between brand price and number of generics: average ratio of inflation-adjusted brand price one year after generic entry to brand price at entry.

Figure 3 illustrates the relationship between brand prices and the number of generics. The horizontal axis reports the number of generics, while the vertical axis depicts the average ratio of brand price at generic entry to inflation-adjusted brand price one year after generic entry. Figure 3 shows that this ratio declines with the number of generics - a finding consistent with our regression results. However, Figure 3 provides an insight not obvious from the regression analysis: the inflation-adjusted brand prices move downward only for brands facing a large of number of generics. Specifically, a year after generic entry, the average brand price is lower than the price at entry only when there are more than 16 generic competitors.

The results presented in Table 5 and Figure 3 suggest that average brand prices responded to generic competition during the 1990s. This finding may reflect higher levels of generic competition in the 1990s than in the 1980s and the willingness of brand firms to decrease prices, at least selectively, to their most important customers. Our results are consistent with a recent study by the $\mathrm{CBO}$ (1998) that found that a brand firm's best price decreases with the number of generic competitors. However, one must keep in mind that the results on Table 5 and Figure 3 capture only the average movement of brand prices. While, on average, brand prices respond to generic entry, the price responses are by no means uniform across drugs and there are significant exceptions. One theoretical explanation for this is that a brand firm's pricing response to generic entry depends in part on life cycle management strategies such as the choice to introduce a product line extension or to shift the brand drug to over-the-counter status. A productive area of future research would be to examine the effects of these and other potential determinants of variation in brands' price responses to generic competition.

\section{Conclusions}

In this paper we have examined the process of generic competition by developing a model that uses a simultaneous equation framework to capture the interactions 
between generic entry, prices, and market shares. Our results suggest that generic market share influences and is influenced by generic prices, supporting the simultaneous equation estimation framework.

We have found generic competition to be particularly intense for blockbuster drugs. These drugs experience significantly more generic entrants, price erosion and generic penetration than other drugs. In turn, we find the number of generic entrants to be a key determinant of the level of generics' share and generic-tobrand price ratio. Contrary to the findings in many previous studies, our results show that brand prices do react to generic competition; each additional entrant is associated with a $0.2 \%$ average decline in brand prices. At the same time, the heterogeneity in the response of brand firm prices to generic entry suggests an important topic for future study.

\section{Notes}

1. Prior to the passage of the 1984 Hatch-Waxman Act, generic firms also needed to do their own safety and efficacy testing on the drug unless this information was part of the public domain.

2. The Hatch-Waxman Act also provided for a listing process for all the brand product's patents with the FDA, and for all legal rules associated with any generic challenges of these patents. The first generic firm to successfully challenge the validity of a brand's patent receives a 180-day exclusivity period before other generics are allowed to enter the market. The law also allows for a stay of up to 30 months while the courts are resolving patent disputes between brand name firms and generic challengers (Federal Trade Commission, 2002).

3. IMS Health estimates that the proportion of pharmacy sales reimbursed at least in part by third parties grew from 37\% in 1990 to $82 \%$ in 1999 (PhRMA, 2000).

4. The Medicaid program and some private health care programs also have instituted maximum allowable cost reimbursement policies, where patients have to pay the full difference between the brand price and generic co-payment if they choose the branded product when a generic is available.

5. Grabowski and Vernon (1996) found that pharmacists earn higher absolute and percentage margins on generic versions of the branded product.

6. Throughout the paper, when we use the phrase 'market share,' we make no attempt to define or imply the relevant antitrust product market; rather, we use 'market share' in its colloquial sense of individual product sales divided by total sales.

7. See, for example, Statman (1981), Masson and Steiner (1985), and CBO (1998). The CBO has examined the pre-1984 period in detail, and concluded that generic competition was concentrated primarily in antibiotics that already had a long-standing abbreviated new drug application process. According to $\mathrm{CBO}$ estimates, generics for 29 non-antibiotic brand name drugs that were among the top 100 selling US prescription drugs had an average market share of just $12.7 \%$. Furthermore, many of the top-selling drugs with expired patents faced no generic competition pre-1984.

8. The selection criterion was drug products that had $\$ 50$ million or more in pre-entry sales. The distribution of sales in pharmaceuticals is highly skewed and entry is concentrated on the largest selling products (Grabowski and Vernon, 1992).

9. They found that the early generic entrants earned most of the profits. Berndt et al. $(1995,1997)$ also found strong first-mover advantages in the case of branded firms.

10. Hudson (2000) has examined the determinants of generic entry and their impact on the original brand product's sales in four countries - the United States, the United Kingdom, Germany, and Japan. Using a common regression equation specification, he finds that generic entry (and entry lag) is positively related to the pre-patent sales. However, the rate of brand sales losses to generics in the United States significantly exceeds that in other countries. This is explained both by the larger size of the US market and the greater incentives in the US that payers, pharmacists, and physicians have to favor generic competition.

11. The issue of marketing intensity prior to patent expiration has also been examined in a recent study by Berndt et al. (2003). 
12. Caves et al. (1991) find that generic entry leads to modest negative effects on brand prices, while Frank and Salkever (1997) find the opposite result, i.e., generic prices lead to higher brand prices. Frank and Salkever (1992) provide a segmented market model to explain this phenomenon. Grabowski and Vernon (1992) essentially observe insignificant differences in the trends in preand post-entry brand prices for most of the products in their sample.

13. Frank and Salkever (1997) undertake an instrumental variable procedure where they predict the number of generics in first stage regression and use the predicted number of generics in a second stage regression to analyse its effect on brand and generic prices.

14. See www.imshealth.com.

15. We did not have extended unit information for all drugs in the dataset.

16. We omitted generic entrants for which the manufacturer description was 'MFG NOT STATED,' 'REPACKAGER,' 'PRIVATE LABEL,' or 'UNIT DOSE LABS' because they do not describe independent firms selling directly through various channels of distribution; these terms generally are used when a brand or generic firm supplies its product to an intermediary that then supplies to the public. The associated entrants, therefore, are not new generic entrants. In recent years, in some cases, generic manufacturers entered at only one dosage strength, and at a dosage not sold by the brand manufacturer. It is difficult to examine this issue using the Generic Spectra dataset because, for most drugs, it contains information only on total grams sold by each generic manufacturer.

17. In creating Table 1, we relied on the Food and Drug Administration's Approved Drug Products with Therapeutic Eqivalence Evaluations report.

18. See www.bls.gov. The pharmaceutical producer price index used is the Drugs and Pharmaceuticals series (not seasonally adjusted) in the Chemical and Allied Products group.

19. Market size is the annual sales (in 2000 dollars) for the brand in the year prior to the first generic entry.

20. The three brands with at least 20 generic manufacturers are Capoten, Xanax, and Zovirax.

21. In the sample there are seven brands with up to two generic manufacturers 12 months after the first generic entry: Aventyl, Carafate, Clozaril, Lozol, Sectral, Toradol, and Zarontin.

22. The 40 drugs in the sample are followed monthly for at most 36 months before and after generic entry. While for many drugs complete information exists for 72 months, several drugs contain data for shorter periods. As a result, the dataset is an un-balanced panel.

23. In Table 1 , the reported generic-to-brand price ratios are at 12 months after generic entry, and the maximum ratio is $76 \%$. In Table 2 , the summary statistics are for all months after entry, and the maximum ratio is $113 \%$. For two drugs, Capozide and Parlodel, the generic price exceeded the brand price in the first month after entry.

24. Parexel's Pharmaceutical R\&D Statistical Sourcebook, 2001, Parexel International Corporation, Waltham, MA, p. 308.

25. The inclusion of the lagged number of generics, $N_{t-1}$, does not imply a lagged dependent variable specification because the explained variable in this estimation equation is not $N_{t}$, the number of generics at period $t$, but $E_{t}$, the number of entrants at period $t$.

26. Under the GLS estimation approach for pooled data, we allow for heteroskedasticity among the cross-sectional units and autoregression within the time series observations for each drug. That is, we estimate for each of the 40 drugs in the sample a different $\sigma$ (standard error of the residuals) and a different $\sigma$ (autoregressive coefficient for the residuals). The GLS model, therefore, nests the OLS framework as a special case wherein all $\sigma$-s are identical and all $\sigma$-s are zero.

27. We use the estimation model to predict the number of entrants for blockbuster and nonblockbuster drugs. The average difference in the predicted entry rate per month between blockbuster and non-blockbuster drugs is 0.15 , which translates to a figure of 1.8 on an annualized basis.

28. To that extent, Model 1's estimation procedure is not OLS but an instrumental variables approach. However, we assume that the error structure of the equation satisfies the assumptions of an OLS approach (i.e., absence of heteroskedasticity and serial correlation). Hence, in discussing the results contained in Table 4, we characterize Model 1's estimation procedure as OLS.

29. The estimated coefficient of the variable, number of generics $(\mathrm{N})$, is -0.0234 ; thus: $\frac{\left.\hat{P}\right|_{\bar{N}}}{\left.\hat{P}\right|_{\bar{N}+1}}=e^{-0.0234}=0.977 ; \quad$ which translates to a $(1-0.977) \times 100=2.3 \%$ decline.

30. The fact that this variable is significant when generic price is present in the equation is consistent with the phenomenon that the more generic firms, the more likely it is that special deals and offinvoice rebates are offered to large purchasers in the distribution chain. 
31. The estimated coefficient of the variable $(\mathrm{N})$, number of generics, is -0.0016 ; thus, denoting deflated brand price as $B \hat{P}$, we have: $\frac{\left.B \hat{P}\right|_{\bar{N}}}{\left.B \hat{P}\right|_{\bar{N}+1}}=e^{-0.0016}=0.9984$; which translates to a (1$0.9984) \times 100=0.16 \%$ decline.

32. As shown in Table 1, the mean number of generic firms after Year 1 is 8.74 , but this number varies positively with market size.

\section{References}

Berndt, E.R. et al. (1995) Information, marketing, and pricing in the US antiulcer drug market, The American Economic Review, 85(2), pp. 100-5.

Berndt, E.R. et al. (1997) The role of marketing, product quality, and price competition in the growth and consumption of US antiulcer drug industry, in: T.F. Bresnahan and R.J. Gordon (Eds) The Economics of New Goods, National Bureau of Economic Research, Studies in Income and Wealth, Vol. 58, pp. 277-328 (Chicago, IL: The University of Chicago Press).

Berndt, E.R. (2002) Pharmaceuticals in US health care: determinants of quantity and price, Journal of Economic Perspectives, 16(4), pp. 45-66.

Berndt, E.R. et al. (2003) The long shadow of patent expiration: generic entry and Rx to OTC switches, in: R.C. Feenstra and M.D. Shapiro (Eds) Scanner Date and Price Indexes, NBER Series on the Conference on Research in Income and Wealth, Vol. 61, pp. 229-67 (Chicago, IL: University of Chicago Press for the National Bureau of Economic Research).

Caves, R.E. et al. (1991) Patent expiration, entry, and competition in the US pharmaceutical industry, Brookings Papers on Economic Activity: Microeconomics 1991, pp. 1-48 (Washington, DC: Brookings Institution Press).

Congressional Budget Office (1998) How Increased Competition from Generic Drugs Has Affected Prices and Returns in the Pharmaceutical Industry (Congressional Budget Office, The Congress of the United States, http://www.cbo.gov/)

Ellison, G. and Ellison, S.F. (2000) Strategic entry deterrence and the behavior of pharmaceutical incumbents prior to patent expiration, Working Paper, MIT.

Federal Trade Commission (2002) Generic drug entry prior to patent expiration: an FTC study, available at: http:/ / www.ftc.gov/os/2002/07/genericdrugstudy.pdf

Food and Drug Administration (1994) Approved Drug Products with Therapeutic Equivalence Evaluations (U.S. Department of Health and Human Services, $14^{\text {th }}$ edition).

Frank, R.G. and Salkever, D.S. (1992) Pricing, patent loss and the market for pharmaceuticals, Southern Economic Journal, 59(2), pp. 165-79.

Frank, R.G. and Salkever, D.S. (1997) Generic entry and pricing of pharmaceuticals, Journal of Economics and Management Strategy, 6(1), pp. 75-90.

Geroski, P. (1995) What do we know about entry?, International Journal of Industrial Organization, 13(4), pp. 421-40.

Grabowski, H.G. and Mullins, C.D. (1997) Pharmacy benefit management, cost-effectiveness analysis, and drug formulary decisions, Social Science E Medicine, 45(4), pp. 535-44.

Grabowski, H.G. and Vernon, J.M. (1992) Brand loyalty, entry, and price competition in pharmaceuticals after the 1984 Drug Act, Journal of Law and Economics, 35(October), pp. 331-50.

Grabowski, H.G. and Vernon, J.M. (1996) Longer patents for increased generic competition in the US: The Hatch-Waxman Act after one decade, PharmacoEconomics, 10(Supplement), pp. 110-23.

Hudson, J. (2000) Generic take-up in the pharmaceutical market following patent expiry: a multicountry study, International Review of Law and Economics, 20(2), pp. 205-21.

Masson, A. and Steiner, R.L. (1985) Generic substitution and prescription drug prices: economic effects of state drug product selection laws, Staff Report, Federal Trade Commission, Bureau of Economics.

Mortimer, R.K. (1997) Demand for prescription drugs: effects of managed care pharmacy benefits, University of California-Berkley, Working Paper No. 97-258, November.

PhRMA (2001) Pharmaceutical Industry Profile 2001: Research for the Millennium, Pharmaceutical Research and Manufacturers of America (Washington, DC).

Reiffen, D. and Ward, M.R. (2002) Generic drug industry dynamics, Working Paper, Federal Trade Commission.

Scott Morton, F.M. (1999) Entry decisions in the generic pharmaceutical industry, RAND Journal of Economics, 30(3), pp. 421-40. 


\section{A. Saha et al.}

Scott Morton, F.M. (2000) Barriers to entry, brand advertising, and generic entry in the U.S pharmaceutical industry, International Journal of Industrial Organization, 18(7), pp. 1085-104.

Statman, M. (1981) The effect of patent expiration on the market position of drugs, in: R.B. Helms, Drugs and Health: Economic Issues and Policy Objectives, pp. 140-50 (American Enterprise Institute).

Wiggins, S.N. and Maness, R. (1994) Price competition in pharmaceutical markets, Unpublished Manuscript, Department of Economics, Texas A\&M University. 